\title{
Effect of Synthetic Auxin Analogs (2.4-D and $\alpha$-NAA) on Growth and Biosynthetic Characteristics of Suspension Cell Culture of Tribulus terrestris L.
}

\author{
S. V. Tomilova ${ }^{a, b}, *$, M. T. Khandy ${ }^{a}$, D. V. Kochkin ${ }^{a, b}$, B. A. Galishev ${ }^{c}$, \\ A. G. Klyushin ${ }^{b}$, and A. M. Nosov ${ }^{a}, b$ \\ ${ }^{a}$ Lomonosov Moscow State University, Moscow, Russia \\ ${ }^{b}$ Timiryazev Institute of Plant Physiology, Russian Academy of Sciences, Moscow, Russia \\ ${ }^{c}$ Ural Federal University, Yekaterinburg, Russia \\ *e-mail: lanatomilova@yandex.ru
}

Received November 5, 2019; revised December 20, 2019; accepted December 23, 2019

\begin{abstract}
Effect of synthetic analogs of auxins-2.4-dichlorophenoxyacetic (2.4-D) and $\alpha$-naphthylacetic $(\alpha-$ NAA) acids - on growth characteristics and accumulation of steroidal glycosides was investigated in suspension cell culture of Tribulus terrestris L. It was found that the substitution of $\alpha$-NAA for 2.4-D in the nutrient medium brought about a rise in the content of steroidal glycosides in the cultured cells (up to six times) and broadened their structural diversity (nine identified oligofurostanosides when growing culture on the medium with $\alpha$-NAA vs. five compounds on the medium with 2.4-D). Positive influence of $\alpha$-NAA exerted on biosynthetic characteristics of T. terrestris suspension cell culture was accompanied by changes in cell morphology (cytodifferentiation), the extent of their aggregation, and gradual decrease (during 3-4 cycles of growing) in culture viability up to its extinction. Simultaneous presence of both synthetic analogs of auxins ( $\alpha$-NAA and 2.4-D) in the growing medium also caused a rise in the content of steroidal glycosides in the cells of T. terrestris, although it was less pronounced (up to three times); however, the culture showed a relatively steady growth and great viability in this case. It was concluded that these two auxin analogs differently influenced the growth of plants' cells in vitro and biosynthesis of substances of specialized metabolism, 2.4-D promoted cell proliferation, whereas $\alpha$-NAA induced cytodifferentiation and activated the production of secondary compounds. This conclusion is corroborated by the data concerning plant cell cultures of other species of medicinal plants accumulating secondary metabolites from other groups. For instance, in the experiments with suspension cell culture of Panax ginseng C.A. Mey., substitution in the growth medium of $\alpha$-NAA for 2.4-D brought about a rise in the content and diversity of triterpene glycosides (ginsenosides) associated with an elevated cell aggregation and deterioration of culture's viability. Comparison of production of steroidal glycosides in plant cell cultures of T. terrestris and Dioscorea deltoidea Wall. that is grown for more than 40 years has shown that both cultures accumulated only furostanol (rather than spirostanol) glycosides that promoted cell proliferation. In suspension cell culture of Dioscorea, a high level of oligofurostanosides (up to $12 \%$ of dry biomass) was accumulated when growing culture on the medium with $2.4-\mathrm{D}$. Thus, investigation into the production of furostanol glycosides in plant cultured cells points to a multifactor system of regulation of secondary metabolism in vitro. Different synthetic auxin analogs may exert alternative influences on growth and biosynthetic processes. At the same time, prolonged culturing leads to an autoselection of cells with the properties promoting proliferation, specifically, with a high content of furostanol glycosides.
\end{abstract}

Keywords: Tribulus terrestris, suspension cell culture, synthetic growth regulators, auxins, steroidal glycosides, furostanol glycosides (oligofurostanosides)

DOI: $10.1134 / \mathrm{S} 1021443720040172$

\section{INTRODUCTION}

Plant cell culture is considered a unique biological system. It enables researchers to investigate various physiological processes occurring on a cellular level.

Abbreviations: FG-furostanol glycosides; UPLC ESI MSultra-high performance liquid chromatography coupled with electrospray ionization mass spectrometry.
In addition to their basic importance, cell cultures may have a practical application in biotechnology as a source of pollution-free plant raw materials containing valuable bioactive substances: secondary metabolites. There are numerous reports that plant cells cultured in vitro have some specific features accounting for the fact that many physiological processes (specifically, secondary metabolism) therein considerably differ 
from such processes in intact plants. This depends on unique properties of the cells living outside the organism: their dedifferentiated state, constant proliferation, and population mechanisms of development [1].

The specificity of plant cell culture as a biological system allows researchers to use it for investigating the mechanisms of cellular regulation of secondary metabolism. Many factors affecting this process (and first of all, the signals that in the cells of intact plants trigger secondary metabolism) have been studied by now. Such signals involve elicitors, stress exposures, and changes in the composition and content of growth regulators [1]. There are indications that the production of secondary metabolites in plant cells cultured in vitro appreciably depends on the qualitative and quantitative composition and the ratio between phytohormones (primarily between auxins and cytokinins or their synthetic analogs) in the cultural medium [1, 2]. However, depending on the kind of cell culture and the type of produced compounds, the effect of these factors on secondary metabolism may differ and general principles are so far not known.

In our previous works with cell cultures of ginseng, we showed that a potent factor affecting the production of secondary metabolites is the composition and content of auxins (or their synthetic analogs) in the growth medium. In the case with cell culture of ginseng Panax ginseng C.A. Mey., the substitution of $\alpha$-NAA for 2.4-D brought about a considerable rise in the content and diversity of triterpene glycosides (ginsenosides) in the cells [2]. At the same time, in the case of Dioscorea deltoidea Wall. cell culture grown for a long time (more than 40 years), 2.4-D alone ensures the intense production of furostanol glycosides (up to $12 \%$ of dry biomass of the cells) [1]. In this relation, it is important to investigate how qualitative and quantitative composition of auxins or their synthetic analogs influences the production of certain types of secondary metabolites in various cell cultures.

Tribulus terrestris L. (Zygophyllaceae R. Br.) synthesizes a wide range of steroidal glycosides possessing a high biological activity (cardiovascular, cytotoxic, and antimicrobial) and is used for the treatment of various diseases [3-5]. Some researchers have produced cell cultures of $T$. terrestris and studied their properties, including the formation of secondary metabolites [6, 7]. We earlier produced T. terrestris callus and suspension cultures, determined their growth parameters, and detected two furostanol glycosides in in vitro cells. In suspension cell cultures, we investigated the effect of heavy metals (copper ions) on the composition and content of steroidal glycosides [8,9].

The aim of this work was to study the effect of composition of synthetic analogs of auxins (2.4-D and $\alpha$-NAA) in the cultural medium on growth and biosynthetic characteristics of suspension cell culture of Tribulus terrestris.

\section{MATERIALS AND METHODS}

As a test subject, we used suspension cell culture of Tribulus terrestris L. (strain Tter 8 deposited at the AllRussia Collection of Cell Cultures of Higher Plants as no. 81) produced by M.T. Khandy with colleagues in Timiryazev Institute of Plant Physiology, Russian Academy of Sciences, in 2014 from callus cell culture induced from the seeds of an American population of T. terrestris (Forever Seeds Company, United States) [8].

The cells were cultured on Murashige and Skoog (MS) medium prepared according to protocol [10] and supplemented with casein hydrolysate $(0.5 \mathrm{~g} / \mathrm{L})$, inositol $(0.1 \mathrm{~g} / \mathrm{L})$, and $3 \%$ sucrose (Merck, Germany). In the experiments, the media were supplemented with various combinations of growth regulators: 2.4-D, BAP, and $\alpha$-NAA (Merck). Concentrations of growth regulators used in the media ranged from 0.5 to $2.0 \mathrm{mg} / \mathrm{L}$. Cell suspensions were cultured in $250-\mathrm{mL}$ flasks (33-35 $\mathrm{mL}$ of suspension per flask) on a rotary shaker $(100 \mathrm{rpm})$ in the dark at $26^{\circ} \mathrm{C}$. The growth cycle of T. terrestris suspension cell culture lasted for 14 days. The cell cultures were passaged at a ratio between inoculum and fresh medium of $1: 10$.

Suspension cell cultures were characterized by cell viability and the content of fresh and dry biomass in $1 \mathrm{~L}$ of medium. Viability of the cells was determined by means of their staining with a vital stain phenosafranine $(0.1 \%$ solution) (Merck) and counting living (nonstained) and dead (stained) cultured units under a microscope. In order to determine fresh and dry biomass, a fixed volume of suspension (at least $30 \mathrm{~mL}$, with three biological replications) was filtered in a vacuum through a paper filter using a Buchner funnel. Biomass was freeze-dried [11].

Photomicrographs of suspension cell cultures were taken using a Levenhuk D2L 0.3 Mpix digital camera (United States).

Qualitative analysis of steroidal glycosides in the experimental types of treatment was made by means of silica gel TLC and ultra-high performance liquid chromatography coupled with electrospray-ionization mass spectrometry (UPLC ESI MS).

A steroidal fraction from freeze-dried biomass was extracted with $70 \%$ ethanol (biomass : solvent $=1: 40$, $\mathrm{w} / \mathrm{v}$ ) on exposure to ultrasound (three times of $30 \mathrm{~min}$ each) at room temperature using a "Sapphire" ultrasonic bath (Russia). The pooled extract was evaporated to dryness in a vacuum at $55^{\circ} \mathrm{C}$ and dissolved in water. The obtained solution was applied to a Supelclean ENVI-18 solid-phase extraction tube (Supelco, United States). The tube was then washed in turn with water and $70 \%$ ethanol. The ethanolic fraction was evaporated to dryness in a vacuum at $55^{\circ} \mathrm{C}$ and used for analysis.

For TLC separation, the purified fraction of steroidal glycosides was dissolved in $70 \%$ ethanol $(0.5-1 \mathrm{~mL})$, and $30 \mu \mathrm{L}$ of the extract was applied on a Kieselgel 60 plate (Merck). As a reference, we used 1\% solution of 
"Deltostim" (a purified mixture of furostanol glycosides protodioscin, 25(S)-protodioscin, deltoside, and $25(S)$-deltoside) from biomass of suspension cell culture of Dioscorea deltoidea Wall. [1]. The volume of "Deltostim" solution applied on the plate was $10 \mu \mathrm{L}$. Furostanol glycosides were separated in a system of solvents chloroform : methanol : water $(65: 35: 10$, by volume). Chromatograms were stained with $1 \%$ Ehrlich's reagent ( $p$-dimethylaminobenzaldehyde, Merck) in a mixture of concentrated hydrochloric acid : ethanol at 34 : 66, by volume, with subsequent heating of the plate at $100^{\circ} \mathrm{C}$ for $5 \mathrm{~min}$. Furostanol glycosides were detected as pinkish-red spots.

The qualitative analysis of steroidal glycosides was carried out using the UPLC ESI MS method; to this end, a sample was dissolved in a mixture acetonitrile : water ( $50: 50$, by volume) and filtered through a nylon filter with $0.2-\mu \mathrm{m}$ pores (Acrodisc, Germany). UPLC ESI MS was performed using a Waters Acquity UPLC system (Waters, United States). A sample $(0.5-1 \mu \mathrm{L})$ was applied to an ACQUITY UPLC BEH Phenyl column $(50 \times 2.1 \mathrm{~mm}, 1.7 \mu \mathrm{m}$, Waters, Ireland $)$. The column temperature was $40^{\circ} \mathrm{C}$, and the volumetric flow rate of the mobile phase was $0.4 \mathrm{~mL} / \mathrm{min}$. As a mobile phase, we used $0.1 \%$ (by volume) aqueous solution of formic acid and $0.1 \%$ (by volume) solution of formic acid in acetonitrile. Chromatographic separation was conducted in the gradient elution mode. In the course of analysis, composition of the mobile phase changed according to the following pattern (acetonitrile, $\%$ by volume): $19 \%$ at $0-7 \mathrm{~min}, 19 \rightarrow 35 \%$ at $7-17 \mathrm{~min}$, $35 \rightarrow 45 \%$ at $17-23 \mathrm{~min}, 45 \rightarrow 55 \%$ at $23-27 \mathrm{~min}$, $55 \rightarrow 65 \%$ at $27-33 \mathrm{~min}, 65 \rightarrow 95 \%$ at $33-33.5 \mathrm{~min}$, $95 \%$ at $33.5-35 \mathrm{~min}, 95 \rightarrow 19 \%$ at $35-35.5 \mathrm{~min}, 19 \%$ at $35.5-37 \mathrm{~min}$. Analysis was performed in the positive-ion mode $(\mathrm{m} / \mathrm{z}$ range of $100-1500)$. Parameters of the ionization source: temperature of ionization source $-120^{\circ} \mathrm{C}$; temperature of desolvation $-250^{\circ} \mathrm{C}$; capillary voltage $-3.0 \mathrm{kV}$; injection cone voltage $-30 \mathrm{~V}$; rate of nitrogen (desolvation gas) feeding $-600 \mathrm{~L} / \mathrm{h}$. The obtained results were processed using MassLynx software (Waters).

Quantitative analysis was made spectrophotometrically as described earlier [9]. Ethanolic extract $(0.4 \mathrm{~mL})$ was put into Eppendorf tubes. The extract was supplemented with $1.0 \mathrm{~mL}$ of the Ehrlich's reagent (1\% solution of $p$-dimethylaminobenzaldehyde in a mixture of concentrated hydrochloric acid : ethanol at $34: 66$, by volume). The tubes were capped and incubated in a thermostat at $50 \pm 1^{\circ} \mathrm{C}$ for $2 \mathrm{~h}$. After cooling, optical density was measured using a "Uniplan" spectrophotometer (ZAO Pikon, Russia) at $520 \mathrm{~nm}$. Concentration of furostanol glycosides was calculated using a calibration curve constructed for "Deltostim" preparation (a mixture of furostanol glycosides isolated from D. deltoidea cell culture).

Growth and physiological characteristics (fresh and dry biomass and viability of cells) were determined with three biological replications. The content of furostanol glycosides was determined in individual extracts without taking into account biological and analytical replications. Figures show the means and their standard errors.

\section{RESULTS}

Suspension cell cultures of T. terrestris were grown on nutrient media with different compositions of phytohormones ( $\alpha$-NAA $(1-2 \mathrm{mg} / \mathrm{L})-\mathrm{BAP}(0.5-2 \mathrm{mg} / \mathrm{L})$ ); control medium contained 2.4-D (2 mg/L)-BAP $(1 \mathrm{mg} / \mathrm{L})$. The experiments have shown that most types of treatment did not display reliable differences during the first cycle of culturing in the accumulation of fresh and dry biomass as compared with control material (Fig. 1). It is interesting that the increment in biomass was greater in the presence of $1 \mathrm{mg} / \mathrm{L} \alpha-\mathrm{NAA}$ and $0.5 \mathrm{mg} / \mathrm{L}$ BAP than in control material and in other types of treatment.

Although the substitution of $\alpha$-NAA for 2.4-D during the first cycle of growing essentially did not influence growth characteristics of $T$. terrestris suspension culture, the viability of the cells decreased in all the experimental types of treatment (media with $\alpha$-NAA). The most pronounced drop in this parameter (less than $40 \%$ of viable cells by the end of culturing) was observed in the presence of $1 \mathrm{mg} / \mathrm{L} \alpha$-NAA and $0.5 \mathrm{mg} / \mathrm{L} \mathrm{BAP} \mathrm{(Fig.} \mathrm{1).}$

For further investigation of growth characteristics during three consecutive culturing cycles, we used two types of media: $2 \mathrm{mg} / \mathrm{L} \alpha-\mathrm{NAA}-1 \mathrm{mg} / \mathrm{L}$ BAP and $1 \mathrm{mg} / \mathrm{L} \alpha-\mathrm{NAA}-1 \mathrm{mg} / \mathrm{L} 2.4-\mathrm{D}-1 \mathrm{mg} / \mathrm{L}$ BAP. In suspension cell culture of $T$. terrestris grown on the medium with $2 \mathrm{mg} / \mathrm{L} \alpha$-NAA and $1 \mathrm{mg} / \mathrm{L}$ BAP, we observed considerable changes in growth characteristics during three consecutive culturing cycles (Fig. 2). It is interesting that the growth of culture essentially ceased during the third cycle and viability of the cells markedly decreased (below 50\%). Moreover, growing of the cell culture with $\alpha$-NAA as an auxin apparently led to prolongation of the period of culturing since the peak of accumulation of fresh and dry biomass was observed only on the 21st day during the second cycle. During three cycles of culturing, we observed the formation of large, dense aggregations and more numerous abnormal cells (Fig. 3).

In suspension cell culture of T. terrestris grown on the medium with the concurrent presence of 2.4-D $(1 \mathrm{mg} / \mathrm{L})$ and $\alpha$-NAA $(1 \mathrm{mg} / \mathrm{L})$, we did not notice a significant decrease in the accumulation of fresh and dry biomass during the three culturing cycles; this is probably related to the presence of 2.4-D (in addition to $\alpha$-NAA) in the nutrient medium (Fig. 4). In this type of treatment, we also observed the elevated aggregation of cell culture (Fig. 5), but the cells remained highly viable (80-90\%) in this case and showed a steady growth over the three cycles of growing. 
(a)
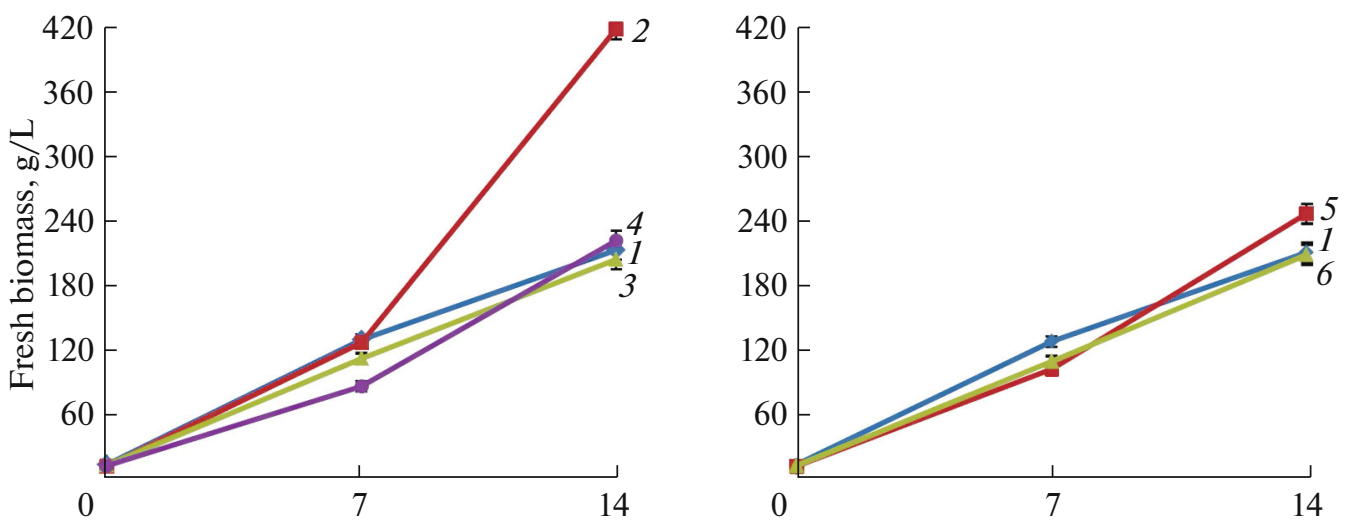

(b)
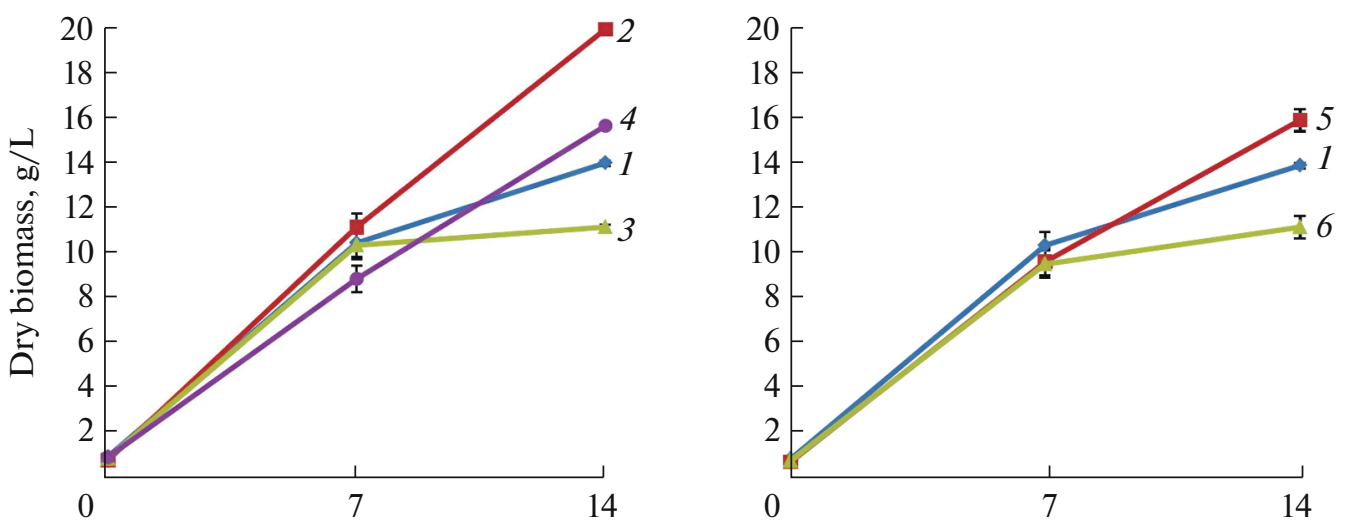

(c)
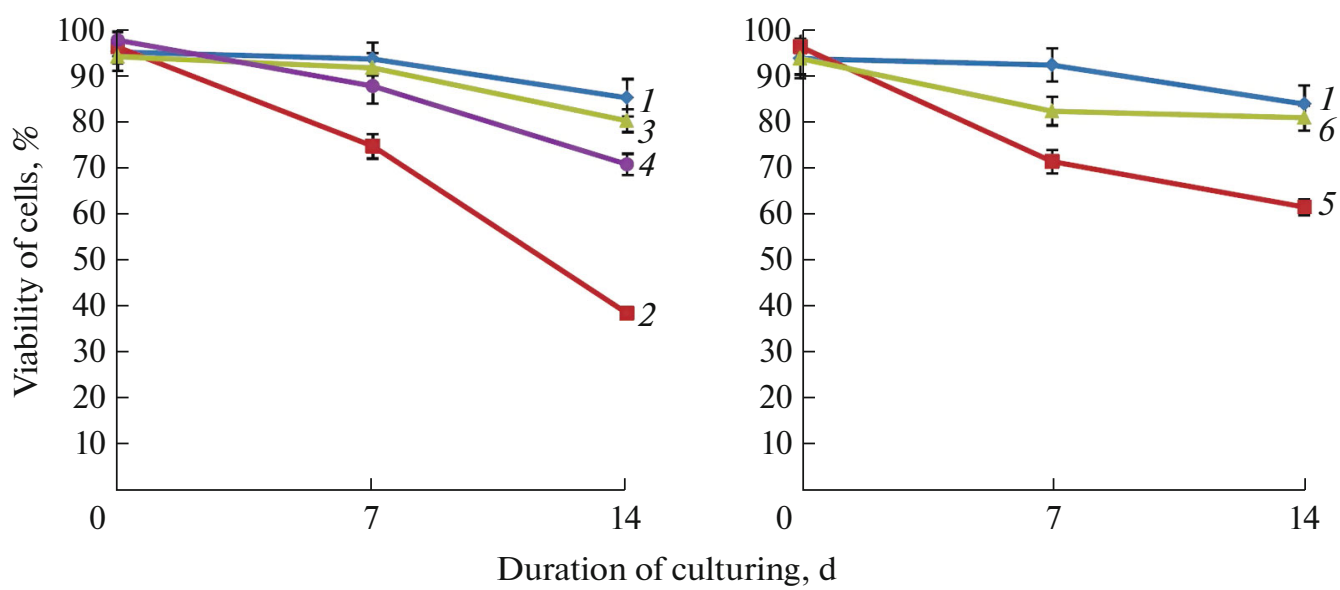

Fig. 1. Fresh (a) and dry (b) biomass and viability (c) of the cells on the seventh and 14th day of growing of T. terrestris suspension culture on the media with different composition of growth regulators: (1) $2 \mathrm{mg} / \mathrm{L} 2.4-\mathrm{D}$ and $1 \mathrm{mg} / \mathrm{L} \mathrm{BAP}$ (control); (2) $1 \mathrm{mg} / \mathrm{L}$ $\alpha$-NAA and $0.5 \mathrm{mg} / \mathrm{L} \mathrm{BAP}$; (3) $1 \mathrm{mg} / \mathrm{L} \alpha-\mathrm{NAA}$ and $1 \mathrm{mg} / \mathrm{L}$ BAP; (4) $1 \mathrm{mg} / \mathrm{L} \alpha-\mathrm{NAA}$ and $2 \mathrm{mg} / \mathrm{L}$ BAP; (5) $2 \mathrm{mg} / \mathrm{L} \alpha-\mathrm{NAA}$ and $2 \mathrm{mg} / \mathrm{L} \mathrm{BAP}$; (6) $2 \mathrm{mg} / \mathrm{L} \alpha-\mathrm{NAA}$ and $1 \mathrm{mg} / \mathrm{L}$ BAP.

Qualitative phytochemical analysis of steroidal glycosides by means of TLC (specific pink staining of the spots with Ehrlich's reagent) has shown the presence of furostanol glycosides (FG) in all the samples of T. terrestris suspension culture. In the extract from bio- mass of cell culture grown in the presence of $\alpha$-NAA alone as a source of auxin, we detected two to seven (in different samples) pinkish-red spots corresponding to FG. In the control type of treatment (medium with $2 \mathrm{mg} / \mathrm{L} 2.4-\mathrm{D}$ and $1 \mathrm{mg} / \mathrm{L} \mathrm{BAP}$ ), we detected only two 

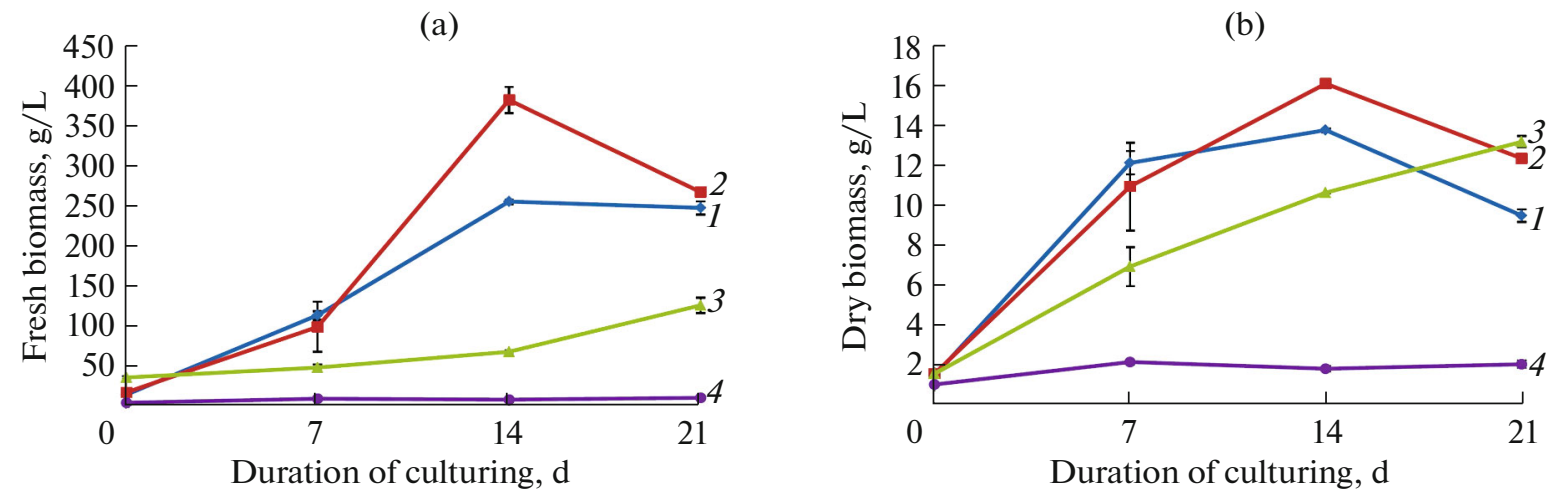

(c)

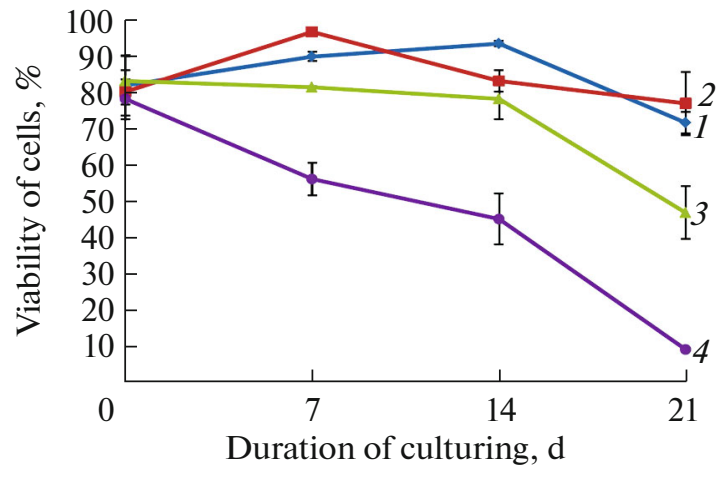

Fig. 2. Accumulation of fresh (a) and dry (b) biomass and viability (c) of the cells during three cycles of growing of T. terrestris suspension culture on the medium with $2 \mathrm{mg} / \mathrm{L} \alpha-\mathrm{NAA}$ and $1 \mathrm{mg} / \mathrm{L} \mathrm{BAP:}$ (1) control (medium with $2 \mathrm{mg} / \mathrm{L} 2.4-\mathrm{D}$ and $1 \mathrm{mg} / \mathrm{L} \mathrm{BAP}$ ); (2) cycle $1 ;$ (3) cycle 2 ; (4) cycle 3.
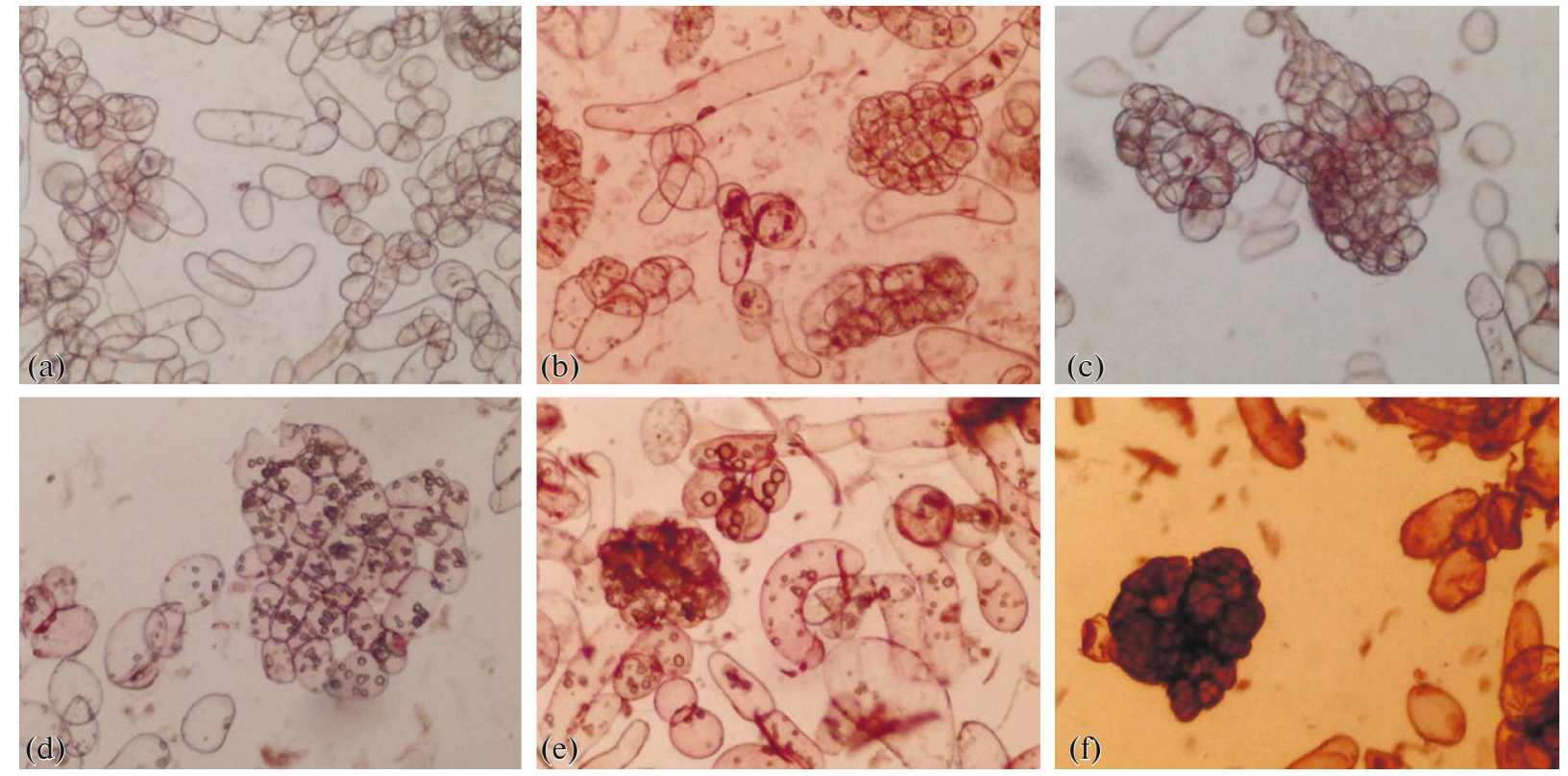

Fig. 3. Photomicrographs of T. terrestris suspension cell culture taken in different stages of growing on the medium with $2 \mathrm{mg} / \mathrm{L}$ $\alpha$-NAA and $1 \mathrm{mg} / \mathrm{L}$ BAP: (a) control, 14 days (medium with $2 \mathrm{mg} / \mathrm{L} 2.4-\mathrm{D}$ and $1 \mathrm{mg} / \mathrm{L}$ BAP); (b) cycle 1, 7 days; (c) cycle 1, 14 days; (d) cycle 2, 7 days; (e) cycle 2, 14 days; (f) cycle 3, 14 days. 

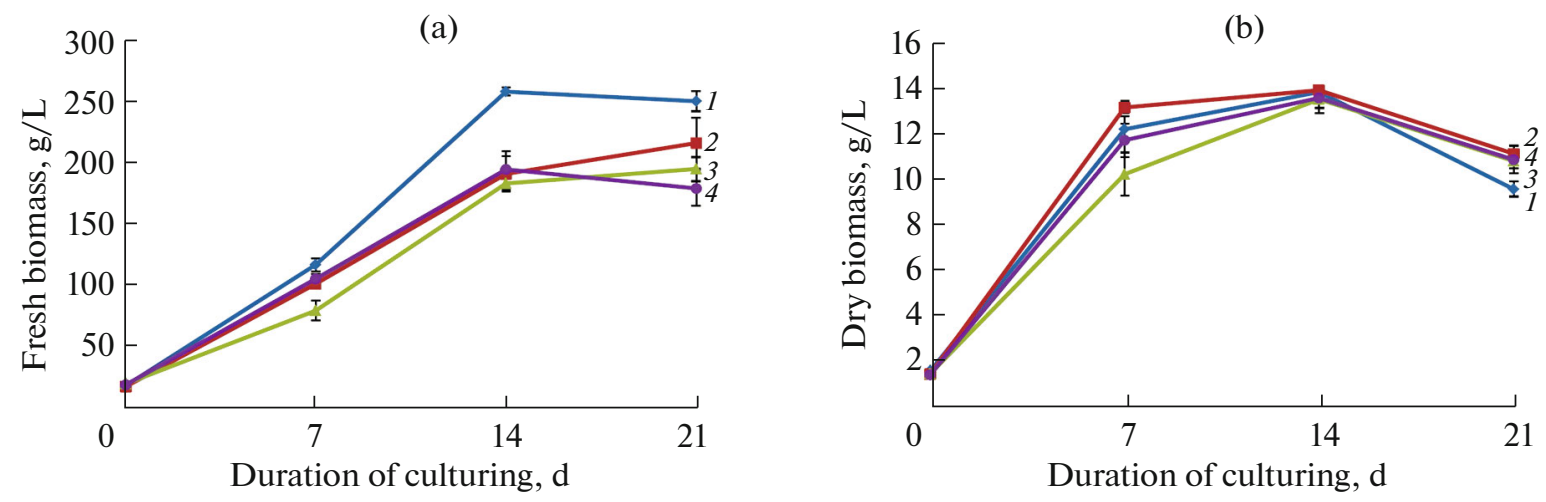

(c)

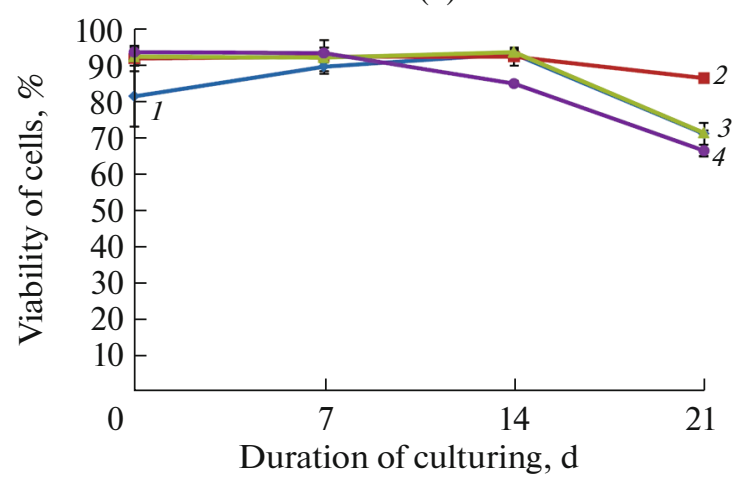

Fig. 4. Accumulation of fresh (a) and dry (b) biomass and viability (c) of the cells during three cycles of growing of T. terrestris suspension culture on the medium with $1 \mathrm{mg} / \mathrm{L} 2.4-\mathrm{D}, 1 \mathrm{mg} / \mathrm{L} \alpha-\mathrm{NAA}$, and $1 \mathrm{mg} / \mathrm{L}$ BAP: (1) control (medium with $2 \mathrm{mg} / \mathrm{L} 2.4-\mathrm{D}$ and $1 \mathrm{mg} / \mathrm{L} \mathrm{BAP}$ ); (2) cycle 1 ; (3) cycle 2; (4) cycle 3.

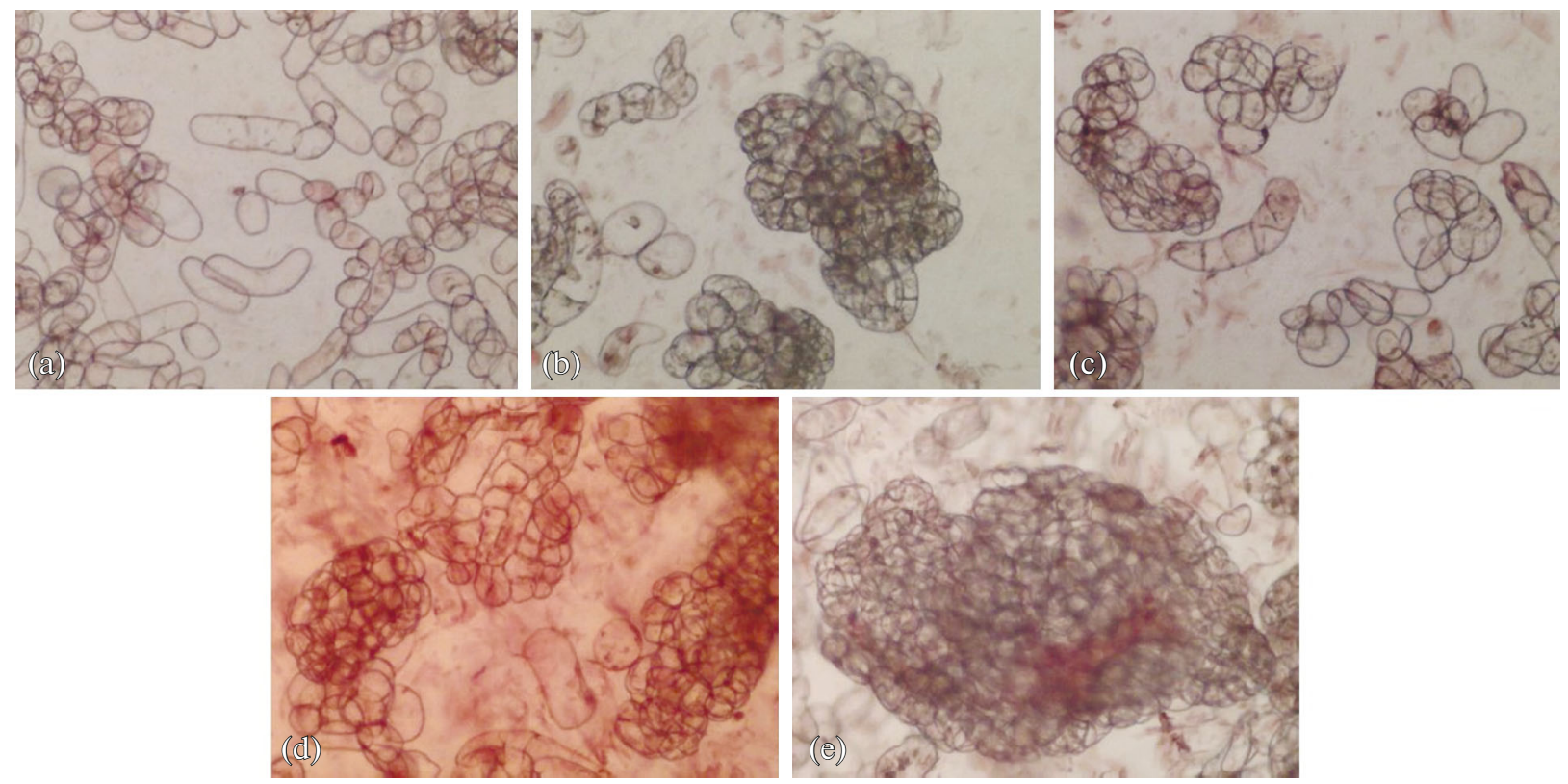

Fig. 5. Photomicrographs of T. terrestris suspension cell culture taken in different cycles of growing on the medium with $1 \mathrm{mg} / \mathrm{L}$ 2.4-D, $1 \mathrm{mg} / \mathrm{L} \alpha$-NAA, and $1 \mathrm{mg} / \mathrm{L}$ BAP: (a) control, 14 days (medium with $2 \mathrm{mg} / \mathrm{L} \mathrm{2.4-D} \mathrm{and} 1 \mathrm{mg} / \mathrm{L}$ BAP); (b) cycle $1,7 \mathrm{days}$; (c) cycle 1,14 days; (d) cycle 2, 14 days; (e) cycle 3, 14 days. 
weakly stained spots of these compounds. On TLC chromatograms of the extracts from biomass of cell culture grown on the media containing both 2.4-D and $\alpha$-NAA, only two spots corresponding to furostanol glycosides were also detected.

The structures of detected compounds were elucidated by means of UPLC ESI MS of purified extracts. UPLC ESI MS chromatograms (the total ion current chromatograms in positive-ion mode) of the extracts from biomass of control culture $(2 \mathrm{mg} / \mathrm{L} 2.4-\mathrm{D}$ and $1 \mathrm{mg} / \mathrm{L}$ BAP, the 14th day of growing) and the culture grown on the medium with $\alpha$-NAA $(2 \mathrm{mg} / \mathrm{L} \alpha-\mathrm{NAA}$ and $1 \mathrm{mg} / \mathrm{L}$ BAP, cycle 2, the 14th day of growing) are shown in Fig. 6.

The structure of compounds was identified on the basis of interpretating the mass spectrometry results (fragmentation of protonated molecules of glycosides in the ionization source), analysis of relative chromatographic behavior of compounds, and comparison of these results with literature data [12, 13]. Results of identification are shown in Table 1. Detected compounds are designated with numbers 1-9 in accordance with the increase in their hydrophobicity (retention time on the reversed-phase of the chromatographic column).

Mass spectrometry showing characteristic fragment ions indicated that detected compounds are derivatives of three different aglycones [3, 12, 13]: compound 1-derivative of hydroxy-diosgenin (characteristic ion $m / z 431$ ); compounds 2 and 3-derivatives of gitogenin/neogitogenin (characteristic ion $\mathrm{m} / z 433$ ); compounds 4-9-derivatives of tigogenin/neotigogenin (characteristic ion $\mathrm{m} / \mathrm{z} 417$ ). Comparison of chromatographic behavior of detected glycosides with literature data corroborates these conclusions. Elution of steroidal glycosides from the reversed-phase mainly

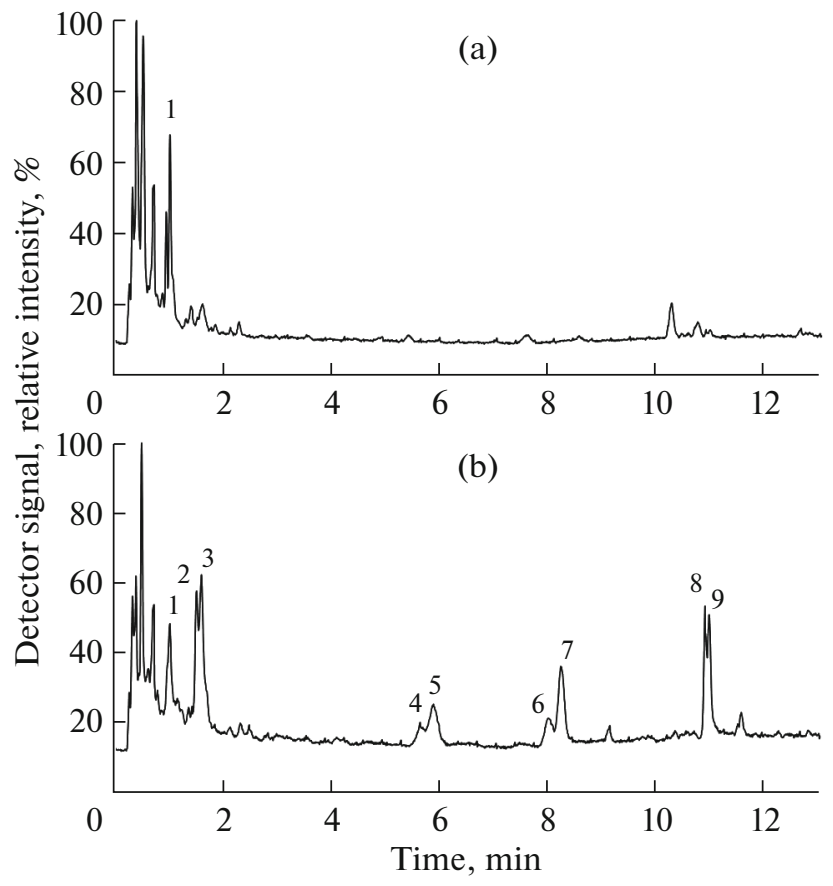

Fig. 6. UPLC ESI MS chromatograms (the total ion current chromatograms in positive-ion mode) of the extracts from biomass of $T$. terrestris suspension cell culture: (a) control $(2 \mathrm{mg} / \mathrm{L} 2.4-\mathrm{D}$ and $1 \mathrm{mg} / \mathrm{L}$ BAP, 14 days of growing); (b) cell culture on the medium with $\alpha$-NAA as a source of auxin $(2 \mathrm{mg} / \mathrm{L} \alpha$-NAA and $1 \mathrm{mg} / \mathrm{L}$ BAP, cycle 2 , 14 days of growing). Numbers $1-9$ show the peaks of identified glycosides (Table 1).

depends on aglycone structure [12, 14]; irrespective of the structure of carbohydrate chains, derivatives containing hydroxyl groups in the cyclic part of molecule (derivatives of hydroxy-diosgenin and gitogenin/neogitogenin) are eluted from the column before unsubsti-

Table 1. Results of UPLC ESI MS analysis (positive-ion mode) of the extracts from biomass of T. terrestris suspension cell culture

\begin{tabular}{|c|c|c|c|c|c|}
\hline \multirow{2}{*}{$\begin{array}{c}\text { Peak } \\
\text { number }\end{array}$} & \multirow{2}{*}{$\begin{array}{l}t_{\mathrm{R}} \\
\min *\end{array}$} & \multicolumn{3}{|c|}{ Mass spectra, $m / z^{* *}$} & \multirow{2}{*}{ Results of identification } \\
\hline & & {$\left[\mathrm{M}-\mathrm{H}_{2} \mathrm{O}+\mathrm{H}\right]^{+}$} & {$[\mathrm{M}+\mathrm{Na}]^{+}$} & Fragment ions & \\
\hline 1 & 1.03 & 1241.6 & 1281.6 & $1079.5,917.5,755.4,593.4,431.3$ & $\begin{array}{l}\text { Pentahexosyl-hydroxy-dios- } \\
\text { genin (furostanol form) }\end{array}$ \\
\hline 2 & 1.52 & 1243.6 & 1283.6 & $1081.6,919.5,757.4,595.4,433.3$ & Pentandroside F \\
\hline 3 & 1.61 & 1243.6 & 1283.6 & $1081.6,919.5,757.4,595.4,433.3$ & $25(R)$-pentandroside $\mathrm{F}$ \\
\hline 4 & 5.63 & 1227.6 & 1267.6 & $1065.6,903.5,741.4,579.4,561.4,417.3$ & Hexosyl-25(S)-terrestrosin $\mathrm{H}$ \\
\hline 5 & 5.88 & 1227.6 & 1267.6 & $1065.6,903.5,741.4,579.4,561.4,417.3$ & Hexosyl-25( $R)$-terrestrosin $\mathrm{H}$ \\
\hline 6 & 7.99 & 1049.5 & 1089.5 & $903.5,887.5,741.4,725.4,579.4,417.3$ & $25(S)$-proto-terrestrosin B \\
\hline 7 & 8.22 & 1049.5 & 1089.5 & $903.5,887.5,741.4,725.4,579.4,417.3$ & $25(R)$-proto-terrestrosin $\mathrm{B}$ \\
\hline 8 & 10.88 & 1313.6 & 1353.6 & $\begin{array}{l}1181.6,1167.6,1049.6,1035.5,1019.6 \\
903.5,887.5,873.5,741.4,579.4,417.3\end{array}$ & Terrestrinin B \\
\hline 9 & 10.95 & 1313.6 & 1353.6 & $\begin{array}{l}\text { 1181.6, 1167.6, 1049.6, 1035.5, 1019.6, } \\
903.5,887.5,873.5,741.4,579.4,417.3\end{array}$ & $25(R)$-terrestrinin $\mathrm{B}$ \\
\hline
\end{tabular}

* Retention time, min; ** data taken from mass spectra $(\mathrm{m} / \mathrm{z}$ values for detected ions are shown). 
tuted compounds (derivatives of tigogenin/neotigogenin).

The widest structural variety of steroidal glycosides (nine compounds altogether) was found in the extract from the biomass of $T$. terrestris cell culture grown on the medium with $\alpha$-NAA. At the same time, biomass of the control culture contained only five glycosides (compounds 1 and 6-9). It is interesting that the intensity of signals of steroidal glycosides on the chromatogram of the extract from control culture biomass is rather low. Therefore, chromatographic peaks of some glycosides (compounds 6-9) on this chromatogram were only detected after filtration of the total ion current by the signals of ions with specific value of $m / z$ (Fig. 7).

Thus, using UPLC ESI MS analysis of biomass of suspension cell culture of $T$. terrestris, we identified nine furostanol glycosides with three different aglycones. It is important that all the detected glycosides had a furostanol structure. Our earlier investigation of cell culture of Dioscorea deltoidea made it possible to assume that producers of steroidal glycosides cultured in vitro (as compared with intact plants) are notable for the accumulation of particularly hydrophilic and nontoxic furostanol forms of these compounds [1]. The data concerning the structural diversity of steroidal glycosides in cell culture of $T$. terrestris obtained in this work corroborate this assumption and point to the general character of this pattern.

The content of steroidal glycosides in suspension cell culture of $T$. terrestris was determined spectrophotometrically for $2 \mathrm{mg} / \mathrm{L} \alpha-\mathrm{NAA}-1 \mathrm{mg} / \mathrm{L}$ BAP and $1 \mathrm{mg} / \mathrm{L} 2.4-\mathrm{D}-1 \mathrm{mg} / \mathrm{L} \alpha-\mathrm{NAA}-1 \mathrm{mg} / \mathrm{L}$ BAP types of treatment. Analysis was made during three cycles of culturing (on the seventh and 14th days of growing for the first cycle; on the 14th day of growing for the second and third cycles). The results are shown in Table 2.

On the nutrient media containing $\alpha$-NAA alone, a 3.3-fold rise in the content of FG was observed as early as on the seventh day of the first cycle as compared with control material ( 3.4 and $1.0 \mathrm{mg} / \mathrm{g}$ dry wt, respectively). The highest, 6.6-fold rise was registered on the 14 th day of the first growing cycle $(6.8 \mathrm{mg} / \mathrm{g}$ dry wt). Subsequently, the content of FG decreased, which was apparently associated with deceleration of growth and deterioration of cell culture viability, but it was 1.31.6 times greater than in control material.

As to suspension cell culture of T. terrestris grown on a mixture of two auxins 2.4-D and $\alpha$-NAA, the content of FG did not increase on the seventh day of the first growing cycle but it rose 1.7 times on the 14 th day as compared with control material (1.8 and $1.0 \mathrm{mg} / \mathrm{g}$ dry wt, respectively). The greatest rise (2.8-fold) in the content of FG occurred on the 14th day of the second growing cycle $(2.9 \mathrm{mg} / \mathrm{g}$ dry wt). Subsequently, this parameter somewhat decreased but remained approximately two times greater than in control cell culture grown on the medium with 2.4-D.

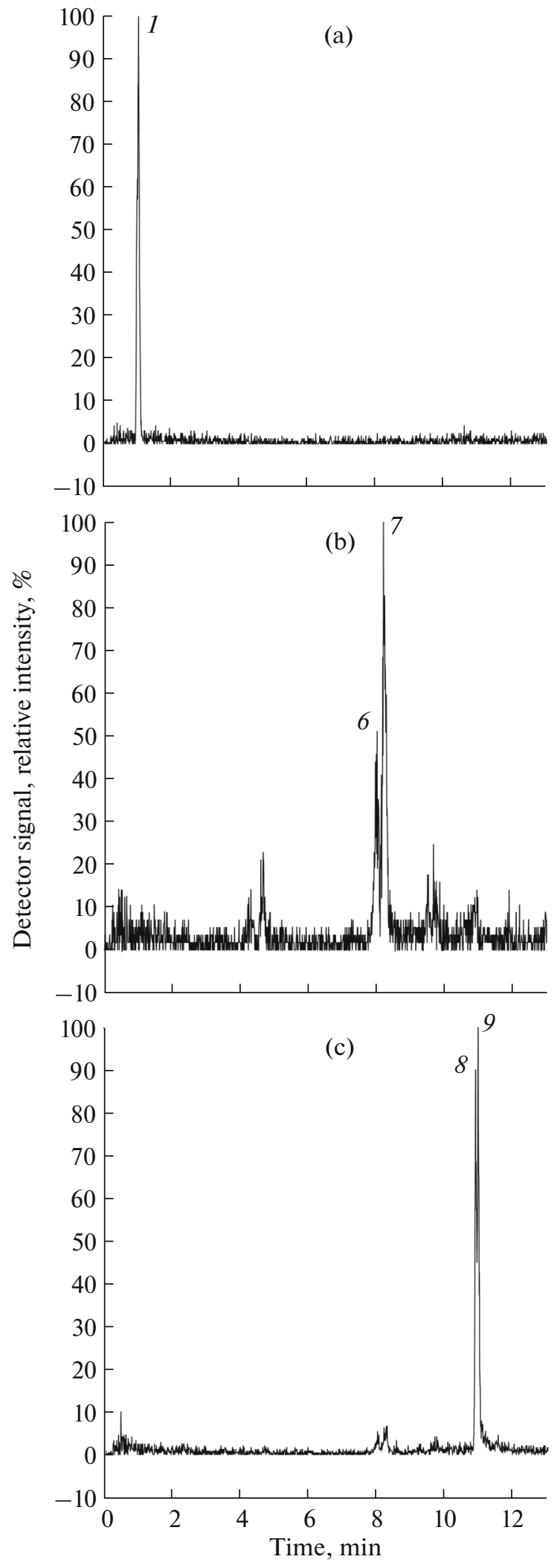

Fig. 7. UPLC ESI MS extracted ion chromatograms (for ions with $m / z 1079.59$ (a), 1049.5 (b), and 887.5 (c) of control T. terrestris suspension cell culture. Numbers 1 and 6-9 show the peaks of identified glycosides (Table 1). 
Table 2. Content of furostanol glycosides (FG) in the biomass of T. terrestris suspension cell culture grown on the media with different composition of growth regulators

\begin{tabular}{l|l|c}
\hline \multicolumn{1}{c|}{ Combination of phytohormones } & \multicolumn{1}{|c}{ Duration of culturing } & Content of FG, mg/g dry wt \\
\hline Control: $2 \mathrm{mg} / \mathrm{L} 2.4-\mathrm{D}, 1 \mathrm{mg} / \mathrm{L}$ BAP & $14 \mathrm{~d}$ & 1.02 \\
\hline \multirow{2}{*}{$\mathrm{mg} / \mathrm{L} \alpha-\mathrm{NAA}, 1 \mathrm{mg} / \mathrm{L}$ BAP } & Cycle $1,7 \mathrm{~d}$ & 3.41 \\
\cline { 2 - 3 } & Cycle $1,14 \mathrm{~d}$ & 6.79 \\
\cline { 2 - 3 } & Cycle 2, 14 d & 1.59 \\
\cline { 2 - 3 } & Cycle 3, 14 d & 1.31 \\
\hline \multirow{2}{*}{$\mathrm{mg} / \mathrm{L} 2.4-\mathrm{D}, 1 \mathrm{mg} / \mathrm{L} \alpha-\mathrm{NAA}, 1 \mathrm{mg} / \mathrm{L}$ BAP } & Cycle $1,7 \mathrm{~d}$ & 0.99 \\
\cline { 2 - 3 } & Cycle 1, 14 d & 1.75 \\
\cline { 2 - 3 } & Cycle 2, 14 d & 2.88 \\
\cline { 2 - 3 } & Cycle 3, 14 d & 1.93 \\
\hline
\end{tabular}

\section{DISCUSSION}

The obtained results suggest that modification of the composition of synthetic analogs of auxins in the nutrient medium on which the culture of $T$. terrestris was grown (substitution of $\alpha$-NAA for 2.4-D) may stimulate in vitro production of steroidal glycosides in the cells. It is important to comment on some peculiarities of such a substitution. (1) Substitution of $\alpha$-NAA for 2.4-D not only elevates (up to six times) the content of the compounds but also modifies their composition (nine identified oligofurostanosides on the medium with $\alpha$-NAA vs. five on the medium with 2.4-D). (2) Widening of the range and accumulation of larger quantities of steroidal glycosides is accompanied by changes in morphology of the cells and the extent of their aggregation as well as a gradual decrease in viability of the culture up to its extinction.

Registered patterns are similar to those we observed earlier upon substitution of $\alpha$-NAA for 2.4-D in cell culture of ginseng $P$. ginseng [2] in respect to compounds of another structural class. In cell culture of ginseng, the range of compounds became wider and the content of triterpene (not steroidal) glycosides (ginsenosides) rose. One may assume that $\alpha$-NAA can act as a signal molecule capable of quick triggering synthesis of secondary metabolites in the cell (like stress exposure or elicitation) and simultaneously inducing differentiation of the cells (many secondary metabolites are synthesized in specialized plant structures). Apparently, these processes depend on the functional role of the metabolites (for instance, participation in stress response, antioxidant activity, etc.) rather than on their chemical structure (triterpene or steroidal glycosides). One can also assume that primary response to the replacement of auxin growth regulators may consist in the modification of physiological status of the cell (its differentiation or interaction with other cells causing aggregation), which induces the production of secondary metabolites. However, such assumptions require proper experimental verification.
It is interesting that the presence in the medium of $\alpha$-NAA as the only auxin brought about quick activation and elevated synthesis of steroidal glycosides but caused the emergence of numerous aggregations, which subsequently led the culture to extinction. Probably, such a response accounts for the dynamics of the content of steroidal glycosides during three consecutive cycles of culturing: the greatest content was observed during the first cycle followed by a fall during the second and third cycles when the culture gradually lost its vital capacity. The combination of two synthetic auxin analogs ( $\alpha$-NAA and 2.4-D) did not cause a prompt activation of synthesis of steroidal glycosides, although it brought about a gradual rise in their content in the biomass; at the same time, the cell culture was notable for a relatively steady growth and great viability that only slightly decreased by the third cycle of growing. One can assert that these two auxin analogs differently influence the processes of proliferation and differentiation of the cells in vitro, which entirely agrees with the literature data [15].

Finally, a comparison of the formation of steroidal glycosides in cell cultures of $D$. deltoidea [1] and T. terrestris shows both similarities and differences in the production of secondary metabolites of the same structural class in these cultures. Both cultures synthesize only furostanol (not spirostanol) glycosides promoting cell proliferation, whereas intact plants produce both forms of these compounds $[3,16]$. This corroborates our earlier assumption [16] about accumulation in the cells in vitro of secondary metabolites promoting cell proliferation. However, active production of furostanol glycosides is promoted by 2.4-D in cell culture of $D$. deltoidea and by $\alpha$-NAA in T. terrestris. This may be accounted for by the fact that cell culture of $D$. deltoidea is a biological system created long ago (its age is over 40); in the course of its formation, actively dividing cells containing compounds promoting proliferation (furostanol glycosides) were selected. Subsequent investigations will show whether or not this pattern is relevant to the T. terrestris cell culture. 


\section{ACKNOWLEDGMENTS}

This work was supported by the Russian Science Foundation, project no. 19-14-00387.

\section{COMPLIANCE WITH ETHICAL STANDARDS}

This article does not contain any studies involving animals or human participants performed by any of the authors.

\section{CONFLICT OF INTEREST}

The authors declare that they have no conflict of interest.

\section{REFERENCES}

1. Nosov, A.M., Popova, E.V., and Kochkin, D.V., Isoprenoid production via plant cell cultures: biosynthesis, accumulation and scaling-up to bioreactors, in Production of Biomass and Bioactive Compounds Using Bioreactor Technology, Paek, K.Y., Murthy, H.N., and Zhong, J.J., Eds., Dordrecht: Springer, 2014, p. 563.

2. Smolenskaya, I.N., Reshetnyak, O.V., Smirnova, Yu.N., Chernyak, N.D., Globa, E.B., Nosov, A.M., and Nosov, A.V., Opposite effects of synthetic auxins, 2,4-dichlorophenoxyacetic acid and 1-naphthalene acetic acid on growth of true ginseng cell culture and synthesis of ginsenosides, Russ. J. Plant Physiol., 2007, vol. 54, p. 215.

3. Kostova, I. and Dinchev, D., Saponins in Tribulus terrestris-chemistry and bioactivity, Phytochem. Rev., 2005, vol. 4, p. 111.

4. Angelova, S., Gospodinova, Z., Krasteva, M., Antov, G., Lozanov, V., Markov, T., Bozhanov, S., Georgieva, E., and Mitev, V., Antitumor activity of Bulgarian herb Tribulus terrestris L. on human breast cancer cells, J. BioSci. Biotechnol., 2013, vol. 2, p. 25.

5. Al-Bayati, F.A. and Al-Mola, H.F., Antibacterial and antifungal activities of different parts of Tribulus terrestris L. growing in Iraq, J. Zhejiang Univ. Sci. B., 2008, vol. 9, p. 154.

6. Erhun, W.O. and Sofowora, A., Callus induction and detection of metabolites in Tribulus terrestris L., J. Plant Physiol., 1986, vol. 123, p. 181.

7. Nikam, T.D., Ebrahimi, M.A., and Patil, V.A., Embryogenic callus culture of Tribulus terrestris L. a poten- tial source of harmaline, harmine and diosgenin, Plant Biotechnol. Rep., 2009, vol. 3, p. 243.

8. Khandy, M.T., Kochkin, D.V., Tomilova, S.V., Galishev, B.A., Sukhanova, E.S., Klyushin, A.G., Ivanov, I.M., and Nosov, A.M., Obtaining and study of callus and suspension plant cell cultures of Tribulus terrestris L., a producer of steroidal glycosides, Appl. Biochem. Microbiol., 2016, vol. 53, p. 800.

9. Tomilova, S.V., Kochkin, D.V., Galishev, B.A., and Nosov, A.M., Effect of elevated concentrations of copper ions on growth characteristics and synthesis of steroidal glycosides in suspension plant cell culture of Tribulus terrestris L., Biotekhnologiya, 2019, vol. 35, p. 42.

10. Murashige, T. and Skoog, F., A revised medium for rapid growth and bio-assays with tobacco tissue cultures, Physiol. Plant., 1962, vol. 15, p. 473.

11. Nosov, A.M., Methods for evaluation and characterization of plant cell culture growth, in Molekulyarno-geneticheskie i biokhimicheskie metody $v$ sovremennoi biologii rastenii (Molecular Genetic and Biochemical Methods in Modern Plant Biology), Kuznetsov, Vl.V., Kuznetsov, V.V., and Romanov, G.A., Eds., Moscow: Binom, Laboratoriya Znanii, 2012, p. 386.

12. Zheng, W., Wang, F., Zhao, Y., Sun, X., Kang, L., Fan, Z., Qiao, L., Yan, R., Liu, S., and Ma, B., Rapid characterization of constituents in Tribulus terrestris from different habitats by UHPLC/Q-TOF MS, J. Am. Soc. Mass Spectrom., 2017, vol. 28, p. 2302.

13. Mulinacci, N., Vignolini, P., la Marca, G., Pieraccini, G., Innocenti, M., and Vincieri, F.F., Food supplements of Tribulus terrestris L.: an HPLC-ESI-MS method for an estimation of the saponin content, Chromatografia, 2003, vol. 57, p. 581.

14. Hamed, A.I., Janda, B., Mahalel, U.A., Stochmal, A., and Oleszek, W., Profiles of steroidal saponins from the aerial parts of Tribulus pentandrus, T. megistopterus subsp. pterocarpus and T. parvispinus by LC-ESI-MS/MS, Phytochem. Anal., 2012, vol. 23, p. 613.

15. Campanoni, P. and Nick, P., Auxin-dependent cell division and cell elongation. 1-Naphthaleneacetic acid and 2,4-dichlorophenoxyacetic acid activate different pathways, Plant Physiol., 2005, vol. 137, p. 939.

16. Nosov, A.M., Application of cell technologies for production of plant-derived bioactive substances of plant origin, Appl. Biochem. Microbiol., 2012, vol. 48, p. 609.

Translated by N. Balakshina 